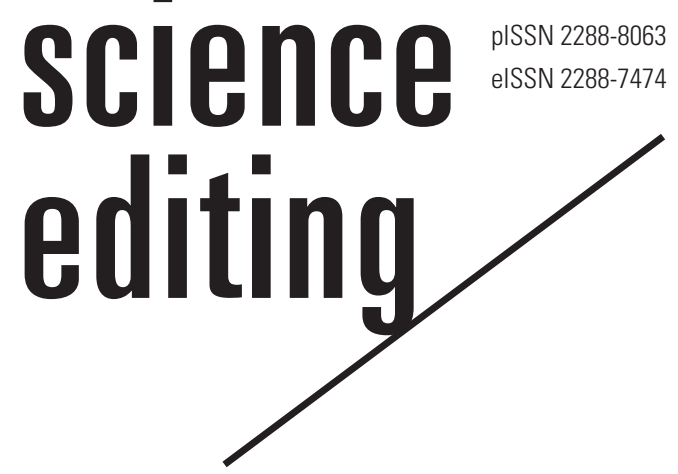

\title{
Compliance of "Principles of transparency and best practice in scholarly publishing" in academic society published journals
}

\author{
Hyung Wook Choi', Ye Jin Choi', Soon Kim² \\ 'Department of Library and Information Science, ${ }^{2}$ Research Institute for Social Science, Ewha Womans University, Seoul, \\ Korea
}

Abstract

Purpose: Four international associations, including the Open Access Scholarly Publishers Association, the Directory of Open Access Journals, the Committee on Publication Ethics, and the World Association of Medical Editors declared the third version of "Principles of transparency and best practice in scholarly publishing" to ensure transparency and quality in journal publications. This study is aimed at assessing the guidelines from the journals' websites manually.

Methods: In this study, three researchers investigate the homepages of 781 academic society-published journals that are registered in the Science Citation Index Expanded and whether these journals are effectively adopting these new guidelines. In this paper, 33 items from the guidelines are examined. The 33 items are rearranged into four different categories: basic journal information; publication ethics; copyright and archiving information; and profit model. The researchers count yes or no after checking the adopting status on the journal homepage and dividing into four scales: $0 \%$ to $25 \%$ for is rarely practiced, $26 \%$ to $50 \%$ for is poorly practiced, $51 \%$ to $75 \%$ for is adequately practiced, and $76 \%$ to $100 \%$ for is well practiced.

Results: Of the 33 items, 10 are found to be poorly or rarely practiced, including readership, data sharing, archiving policies, and profit model information.

Received: June 22, 2019 Accepted: June 29, 2019

Correspondence to Soon Kim soonkim123@ewhain.net

ORCID

Hyung Wook Choi

https://orcid.org/0000-0002-4075-0768 Ye Jin Choi

https://orcid.org/0000-0002-4155-2093 Soon Kim

https://orcid.org/0000-0001-7154-2809
Conclusion: It could be the most up-to-date indicator of the current status of applying best practice guidelines. Society journal editors especially from Asia should evaluate their journals regarding "Principles of transparency and best practice in scholarly publishing".

Keywords

Best practice; Scholarly publishing; Academic society journals; Transparency; Publication ethics 


\section{Introduction}

A high level of trust is essential to ensure publication and sharing of research results. However, the amount of unethical research is increasing, and so-called "predatory" journals have been rapidly appearing over the past decade. Although publishing practices vary by discipline or region, common ethical standards exist to ensure trusted peer-reviewed journals at the highest level. In an attempt to combat the rise of unethical and suspicious journals, the International Association of Scientific, Technical, and Medical Publishers (STM) announced the "STM statement on the increase of unethical and deceptive journal practices." The STM is not only actively supporting both the Committee on Publication Ethics (COPE) and the Think. Check. Submit initiative; it is also strictly applying the Code of Conduct and the policy on "international ethical principles for scholarly publication" to its members [1].

Another four international associations, including the Open Access Scholarly Publishers Association, the Directory of Open Access Journals, the COPE, and the World Association of Medical Editors, declared the third version of the "Principles of transparency and best practice in scholarly publishing," which was first published in 2013 to ensure transparency and quality in journal publications. Although this guideline was announced in January 2018, many journals are still unaware of the Principles, which include transparent journal information on the homepage, editorial boards, peer review, author publication charge, publication ethics, archiving, and accessibility. The four associations are promoting good practices through the 16 Principles, and each uses them in its own way along with other information to assess membership applications. They also require all existing members to comply with the Code of Conduct that prohibits misconduct. If any member of the organization violates the guidelines or other requirements, their membership may be suspended or terminated if they are unable to resolve the matter.

The United States National Library of Medicine uses the Principles when reviewing an application for PubMed Central. If the necessary conditions are not met, the applicant will not be considered past the initial screening stage. PubMed Central has begun monitoring for style and format more thoroughly than in the past [2]. Hence, journal editors in the medical field who want to register their journal on PubMed Central should pay attention to this best practice guideline.

We can assume that commercial publishers with abundant human resources and financial support can more easily add these kinds of materials to a template webpage comparing academic societies. Thus, in this paper, only scholarly journals published by academic societies were checked for proper implementation of the guidelines.
Although active discussions have been ongoing concerning the Principles, no exhaustive study has been conducted on the status of scholarly journal compliance. Because the guidelines were recently revised in January 2018, few scholarly journals have adopted them correctly. This researcher found that only one study was presented in the European Association of Science Editors Conference that investigated whether 10 Trakya University-published journals were following the Principles. The overall compliance rate of these journals was 49\% [3]. Because the guidelines are relatively new to the journal edi-

Table 1. Sixteen original "Principles of transparency and best practice in scholarly publishing"

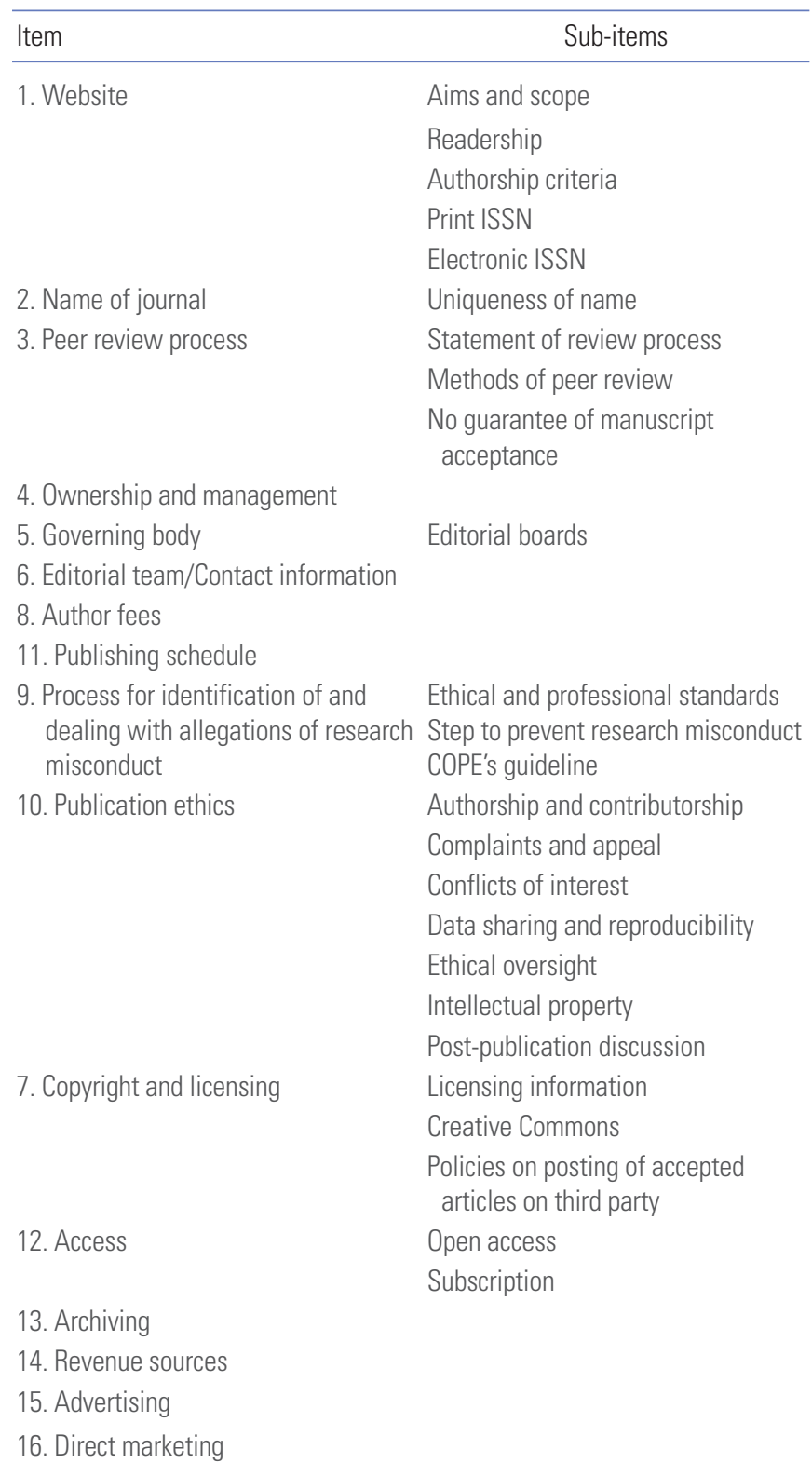

ISSN, Standard Serial Number; COPE, Committee on Publication Ethics. 
Table 2. Sixteen original principles sub-divided into 33 items and categorized into four different subjects [4]

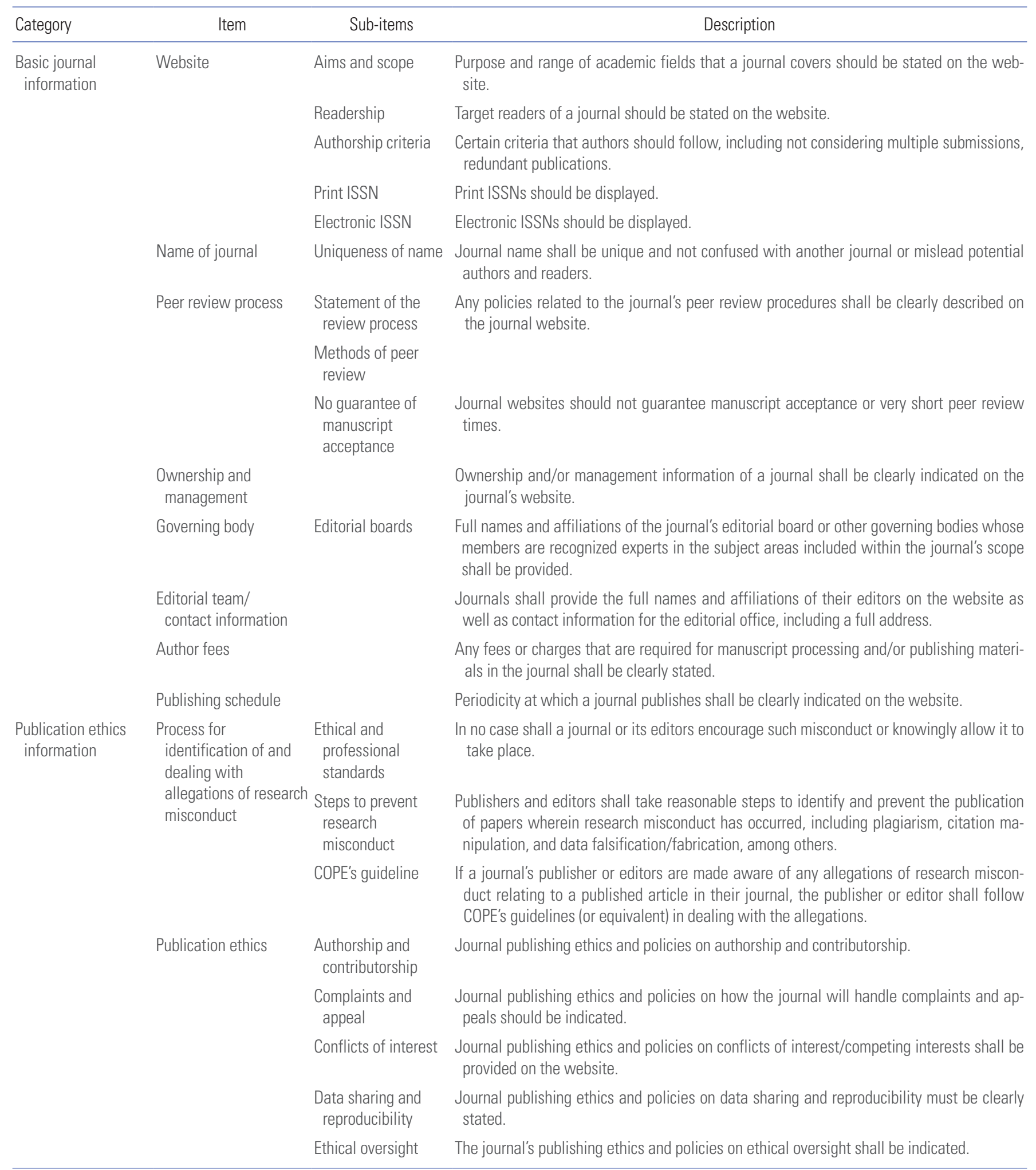


Table 2. Continued

\begin{tabular}{|c|c|c|c|}
\hline Category & Item & Sub-items & Description \\
\hline & & $\begin{array}{l}\text { Post-publication } \\
\text { discussion }\end{array}$ & The journal's options for post-publication discussions and corrections shall be provided. \\
\hline \multirow{3}{*}{$\begin{array}{l}\text { Copyright and } \\
\text { archiving } \\
\text { information }\end{array}$} & Copyright and licensing & Licensing information & $\begin{array}{l}\text { Licensing information shall be clearly described in the guidelines on the website, and li- } \\
\text { censing terms shall be indicated on all published articles, in both HTML and PDF format. }\end{array}$ \\
\hline & & $\begin{array}{l}\text { Policies on posting } \\
\text { accepted articles } \\
\text { with third parties }\end{array}$ & $\begin{array}{l}\text { Any policies on the posting of final accepted versions or published articles on third-party } \\
\text { repositories shall be clearly stated. }\end{array}$ \\
\hline & Access & Open access & $\begin{array}{l}\text { The way(s) in which the journal and individual articles are available to readers and wheth- } \\
\text { er there is an associated subscription or pay-per-view fees shall be stated. }\end{array}$ \\
\hline \multirow{3}{*}{$\begin{array}{l}\text { Profit model } \\
\text { information }\end{array}$} & Revenue sources & & Business models or revenue sources shall be clearly stated on the journal's website. \\
\hline & Advertising & & $\begin{array}{l}\text { A journal shall indicate its advertising policy if relevant, including what types of adverts } \\
\text { will be considered, who makes decisions regarding accepting adverts, and whether they } \\
\text { are linked to content or reader behavior or are displayed at random. }\end{array}$ \\
\hline & Direct marketing & & $\begin{array}{l}\text { Any direct marketing activities, including solicitation of manuscripts that are conducted on } \\
\text { behalf of the journal, shall be appropriate, well targeted, and unobtrusive. }\end{array}$ \\
\hline
\end{tabular}

ISSN, Standard Serial Number; COPE, Committee on Publication Ethics.

tors, they have many areas that could be further enhanced. Therefore, the author of this paper explores how publishers respond and conform to the guidelines of the "Principles of transparency and best practice in scholarly publishing (Table 1)," as announced in January 2018.

\section{Methods}

\section{Data collection}

To investigate how the Principles are applied in academic society journals, a list of Science Citation Index Expanded journals was downloaded from the Clarivate Analytics website in July 2018. Among 9,058 journals, 984 that had "ASSOC," "SOC," or "SOC" in their address information were extracted. Furthermore, because the researchers could manually distinguish the journals from South Korea, 104 South Korean journals were collected. Duplicated data from all extracted data were excluded. Thereafter, 65 journals that were not offered in English, 135 that were using platforms from commercial publishers, and 41 with access problems were also excluded. Finally, a total of 781 journals were selected and manually combed for adherence to the Principles. All the journal's websites were accessed between October 1 and November 26,
2018 by the three researchers.

To increase the reliability of data collection, the researchers collected data from 30 of the same websites as a beta-test and came to a consensus regarding the items that they found difficult to measure before starting actual data collection. Then, to ensure that the researchers conducted the data collection with consent, $10 \%$ of the data (80 journals' homepages) were randomly selected and checked again by another researcher so that the journals were examined under the same standard.

\section{Data analysis}

Based on collected data, the 16 best practices were divided into four different categories: basic journal information; publication ethics information; copyright and archiving information; and profit model information, as shown in Table 2 [4]. In the process of checking each practice, the 16 practices were specified with sub-items, and a total of 33 items were checked manually through journal websites. The arrangement of items was changed during this process. The definitions were drawn directly from the "Principles of transparency and best practice in scholarly publishing" [4] to elaborate on each specific subitem in categories.

In addition, to evaluate each sub-item with a yes response, 
the responses from 781 journals were divided into four scales: $0 \%$ to $25 \%$ for rarely practiced, $26 \%$ to $50 \%$ for poorly practiced, $51 \%$ to $75 \%$ for adequately practiced, and $76 \%$ to $100 \%$ for well practiced.

Moreover, to account for regional distribution, countries were categorized into one of six continents (Africa, Asia, Europe, North America, South America, and Oceania) using address information from the journal list (Table 3).

\section{Results}

\section{Basic journal information}

Among those 14 specific items of basic journal information, 11 items were well or adequately practiced on the websites, as shown in Fig. 1. Readership and author fees were classified as poorly practiced items because only $50 \%$ or fewer of the journals stated the items on their homepages.

Table 3. Based on each journal's address, collected data were categorized into one of six continents

\begin{tabular}{lcc}
\hline Continent & Count & Percentage \\
\hline North America & 435 & 55.7 \\
Asia & 133 & 17.0 \\
Europe & 174 & 22.3 \\
South America & 26 & 3.3 \\
Oceania & 7 & 0.9 \\
Africa & 6 & 0.8 \\
Total & 781 & 100.0 \\
\hline
\end{tabular}

In the case of methods of peer review, specific data were collected as shown in Table 4 (Dataset 1). Among 781 journals, 185 stated their detailed review process. The most common type was single-blind, followed by double-blind. However, 596 journals did not provide specific methods of peer review.

Based on a continent distribution analysis, two poorly practiced items were analyzed in Table 5. The readership item was indicated by only $33 \%$ of total journals. More of the journals in Europe and Asia did not follow the readership item than in North America.

\section{Publication ethics information}

Among the ten items, six were found to be adequately practiced (Fig. 2). In the publication ethics information category, there was no item that was well practiced. In particular, COPE's guideline; data sharing and reproducibility; and postpublication discussion were poorly practiced, with only $26 \%$ to $50 \%$ of journals indicating these items on their websites.

Three poorly practiced items were analyzed for continent distribution analysis, as shown in Table 6. The findings showed that COPE's guideline; data sharing and reproducibility; and post-publication discussion were not clearly indicated on a large number of journal homepages. Data sharing and reproducibility was indicated among only $8 \%$ of Asian journals but $36 \%$ of North American journals. Post-publication discussion was indicated among 6\% of Asian journals compared to $61 \%$ of European journals.

\section{Copyright and archiving information}

Among the five items collected, copyright and licensing information was proven to be well practiced, and Creative Com-

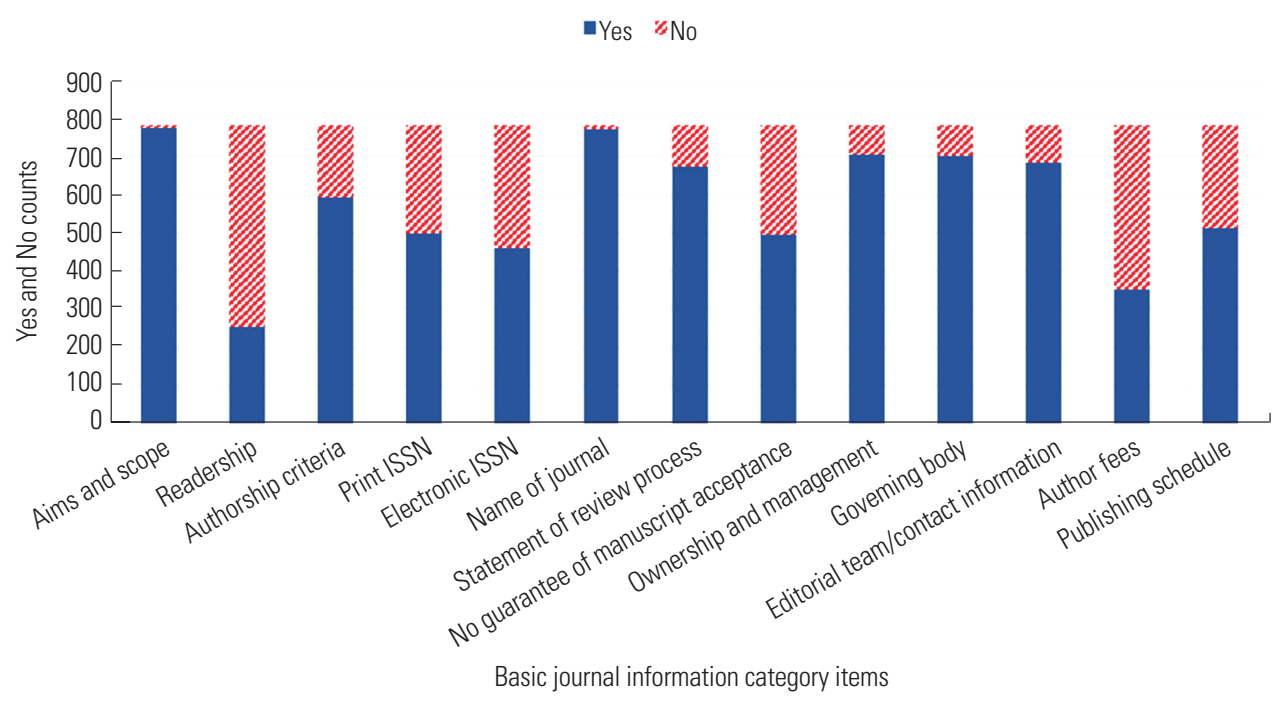

Fig. 1. Fourteen items in the basic journal information category (X-axis) were searched on 781 journals' websites for whether the items were indicated clearly and counted as "yes" or "no." ISSN, International Standard Serial Number. 
mons and open-access items were adequately practiced (Fig. 3). Policies on the posting of accepted articles with third parties, subscription, and archiving were classified as poorly practiced. Number of journals which allowed open access to the electronic edition and required a subscription for the print edition was 288 .

Two poorly practiced items were analyzed by continent

Table 4. Specific types of peer review methods as indicated on 781 journals' websites

\begin{tabular}{lc}
\hline Specific type & Count \\
\hline No information & 596 \\
Open peer review & 3 \\
Single-blind & 92 \\
Double-blind & 89 \\
Triple-blind & 1 \\
Total & 781
\end{tabular}

distribution, as shown in Table 7. Policies on the posting of accepted articles with third parties and archiving were mostly found to be not clearly indicated in this category. The "yes" percentage in Asia, especially for policies on the posting of accepted articles on the third party, was comparatively lower than for other continents.

\section{Profit model information}

Among the three items in this category, all were classified as poorly or rarely practiced (Fig. 4). In particular, revenue sources were rarely practiced. No more than $20 \%$ of journals indicated this information on their homepage. The profit model information category can be characterized as a poorly practiced category overall.

This category was poorly or rarely practiced overall, as shown in Table 8. Two items, advertising and direct marketing, were poorly practiced items, and the revenue source item was seldom practiced.

Table 5. Two poorly practiced items in basic journal information

\begin{tabular}{|c|c|c|c|c|c|c|c|c|c|}
\hline \multirow{2}{*}{ Item } & \multirow{2}{*}{\multicolumn{2}{|c|}{ Count/percentage }} & \multicolumn{6}{|c|}{ Continent } & \multirow{2}{*}{ Total } \\
\hline & & & North America & Asia & Europe & South America & Oceania & Africa & \\
\hline \multirow[t]{2}{*}{ Readership } & Yes & Count & 155 & 32 & 54 & 8 & 4 & 1 & 254 \\
\hline & & Percentage & 36 & 24 & 31 & 31 & 57 & 17 & 33 \\
\hline \multirow[t]{2}{*}{ Author fees } & Yes & Count & 187 & 78 & 76 & 5 & 3 & 3 & 352 \\
\hline & & Percentage & 43 & 59 & 44 & 19 & 43 & 50 & 45 \\
\hline
\end{tabular}

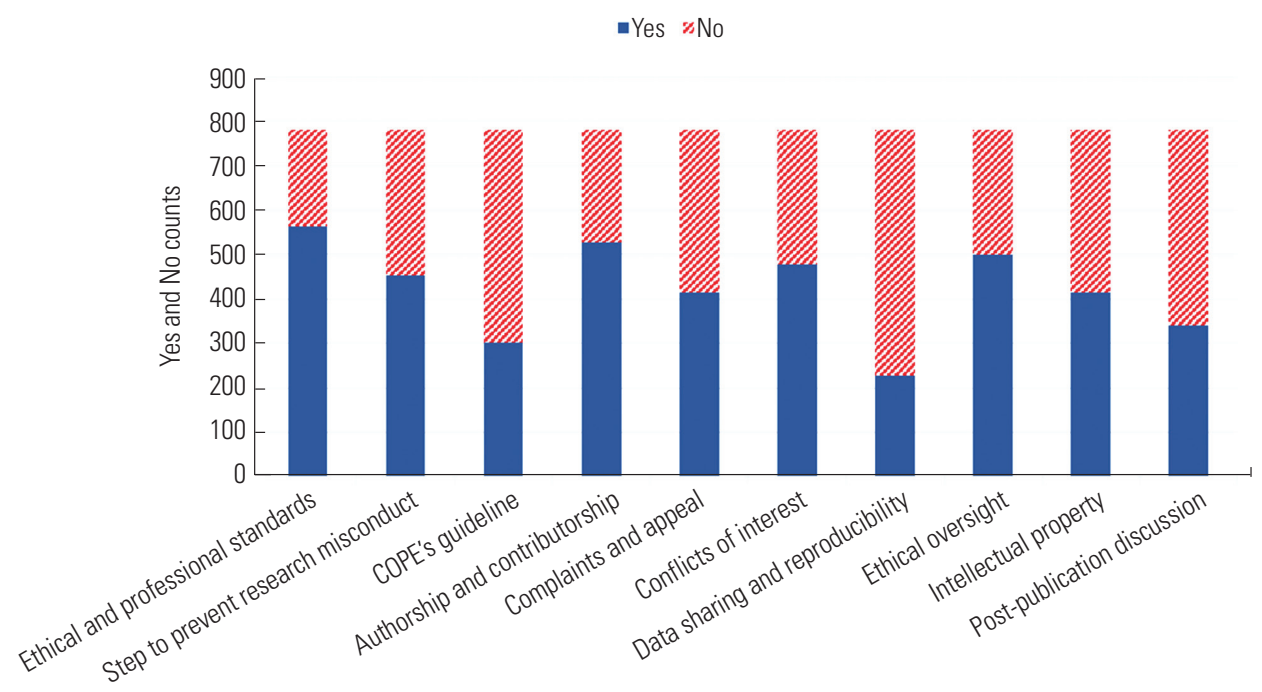

Public ethics information category items

Fig. 2. Ten items in the publication ethics information category (X-axis) were searched on 781 journals' websites for whether the items were indicated clearly and counted as "yes" or "no." COPE, Committee on Publication Ethics. 
Table 6. Three poorly practiced items in publication ethics information

\begin{tabular}{|c|c|c|c|c|c|c|c|c|c|}
\hline \multirow[b]{2}{*}{ Item } & \multirow{2}{*}{\multicolumn{2}{|c|}{ Count/percentage }} & \multicolumn{6}{|c|}{ Continent } & \multirow[b]{2}{*}{ Total } \\
\hline & & & $\begin{array}{c}\text { North } \\
\text { America }\end{array}$ & Asia & Europe & $\begin{array}{c}\text { South } \\
\text { America }\end{array}$ & Oceania & Africa & \\
\hline COPE's guideline & & Percentage & 36 & 38 & 55 & 12 & 0 & 0 & 39 \\
\hline Data sharing and reproducibility & Yes & Count & 158 & 10 & 54 & 4 & 1 & 0 & 227 \\
\hline \multirow[t]{2}{*}{ Post-publication discussion } & Yes & Count & 218 & 8 & 106 & 6 & 1 & 0 & 339 \\
\hline & & Percentage & 50 & 6 & 61 & 23 & 14 & 0 & 43 \\
\hline
\end{tabular}

COPE, Committee on Publication Ethics.

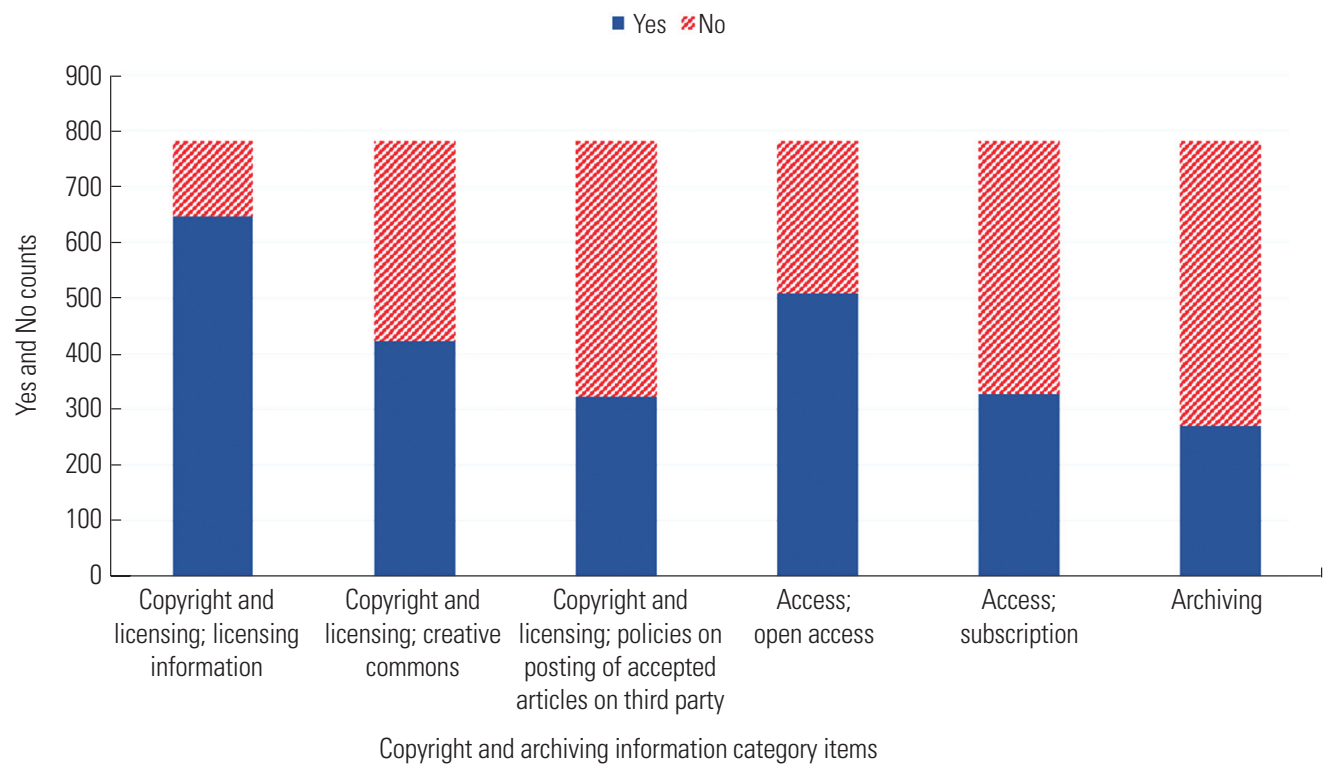

Fig. 3. Five items in the copyright and archiving information category (X-axis) were searched on 781 journals' websites for whether the items were indicated clearly and counted as "yes" or "no."

Table 7. Two poorly practiced items in copyright and archiving information

\begin{tabular}{|c|c|c|c|c|c|c|c|c|c|}
\hline Item & \multicolumn{2}{|c|}{ Count/percentage } & \multicolumn{6}{|c|}{ Continent } & Total \\
\hline Policies on posting of & Yes & Count & 210 & 10 & 95 & 4 & 1 & 1 & 321 \\
\hline accepted articles on third party & & Percentage & 48 & 8 & 55 & 15 & 14 & 17 & 41 \\
\hline Archiving & Yes & Count & 111 & 47 & 107 & 1 & 2 & 1 & 269 \\
\hline
\end{tabular}

\section{Discussion}

This study revealed 10 poorly practiced items among 33 subitems of the "Principles of transparency and best practice in scholarly publishing" in academic society-published journals. We found different patterns of geographic variation in compliance within each category. Whether individual journals were predominantly compliant or not was dependent on the 
Table 8. Three poorly or rarely practiced items in profit model information

\begin{tabular}{|c|c|c|c|c|c|c|c|c|c|}
\hline \multirow{2}{*}{ Item } & \multirow{2}{*}{\multicolumn{2}{|c|}{ Count/percentage }} & \multicolumn{6}{|c|}{ Continent } & \multirow[b]{2}{*}{ Total } \\
\hline & & & North & Asia & Furnne & South & Осеапіа & Africa & \\
\hline \multirow[t]{2}{*}{ Revenue sources } & Yes & Count & 73 & 4 & 76 & 3 & 1 & 1 & 158 \\
\hline & & Percentage & 17 & 3 & 44 & 12 & 14 & 17 & 20 \\
\hline \multirow[t]{2}{*}{ Advertising } & Yes & Count & 178 & 7 & 91 & 4 & 4 & 0 & 284 \\
\hline & & Percentage & 41 & 5 & 52 & 15 & 57 & 0 & 36 \\
\hline \multirow[t]{2}{*}{ Direct marketing } & Yes & Count & 152 & 5 & 40 & 2 & 1 & 0 & 200 \\
\hline & & Percentage & 35 & 4 & 23 & 8 & 14 & 0 & 26 \\
\hline
\end{tabular}

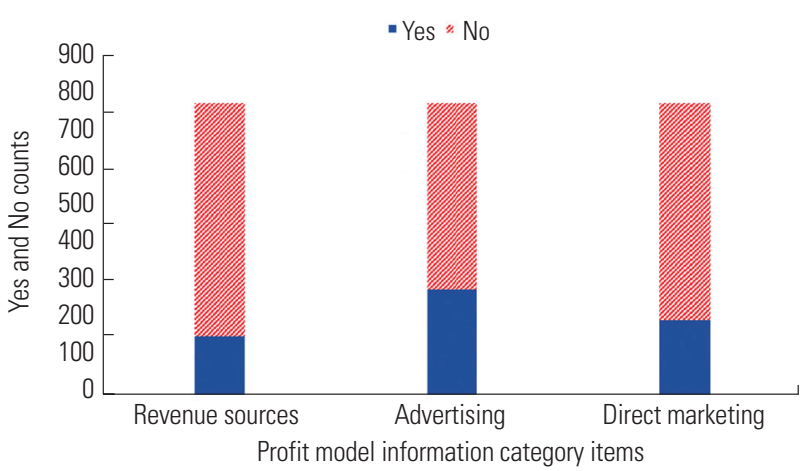

Fig. 4. Three items in the profit model information category (X-axis) were searched on 781 journals' websites for whether the items were indicated clearly and counted as "yes" or "no."

scientific society to which they belonged. For example, the World Journal of Men's Health, a Korean journal, was compliant with all 33 sub-items, while journals belonging to large societies, such as the American Chemical Society or Royal Society of Chemistry, were not compliant with all these items. Based on this result, we could estimate that editors' or societies' interest in this best practice guideline was the deciding factor in whether they implemented it.

\section{Geographic variation in compliance}

European journals were complying well with most best-practice guidelines compared with their Asian and North American counterparts. In particular, Asian journals rarely practiced "data sharing and reproducibility," "policies on posting accepted articles on third-party websites" and "post-publication discussion." "Archiving" were mostly found to be not indicated in North America. Especially for this item, the "yes" percentage was higher among Asian than North American journals. Considering the growing number of research funders who are asking to mandate open access policies in European countries, the perception of such policies is less favorable in Asian countries.
Regardless of continents, all items from the profit model information category were poorly or rarely practiced.

\section{Basic journal information}

In the basic journal information category, the readership item was most significantly poorly practiced by journals. Academic publishing depends greatly on trust because authors and readers believe that editors will conduct a fair peer-review process as per the information provided on the journal homepage. The items, not only "readership" but also "no guarantee of manuscript acceptance," are easily revised on the journal homepage. These items could be the first improvement target to meet the best-practice guidelines.

Good management of these contents will foster a sustainable publishing infrastructure, which will benefit all stakeholders in the publishing process [5]. Because the most critical journal information is described in this section, journal editors should pay close attention to implementing these basic journal information items well.

\section{Publication ethics information}

The proportion of poorly practiced items is higher in the publication ethics category compared to basic journal information. In particular, "data sharing and reproducibility" and "post-publication discussion" are rarely practiced in Asia compared to Western countries. A great deal of research has been conducted on data sharing from the perspective of researchers; however, few studies have been performed on compliance with this policy from the perspective of journal editors. According to a recent study by Kim et al. [6] in a survey of 100 Korean scholarly journals, only 13 stated that they had already adopted a data sharing policy.

Data-sharing policies may differ according to the journal's situation. Such a policy can have a positive effect because it enables more in-depth research using already existing data. PLOS has explicitly stated that data must be made publicly 
available, and rare exceptions must be agreed with the editor [7]. Vines et al. [8] proved that journals with an archiving policy have 25 times higher data availability than those with no such policy. Stating the data sharing policy in the author guidelines makes the authors actively participate in data archiving, which is highly germane to the success of an open data policy. Hence, the detailed adoption level should be announced on the journal homepage.

\section{Copyright and archiving information}

Policies on the posting of accepted articles with third parties are the most poorly practiced item in this category, and Asian journals performed comparatively worse than other continents in this regard.

SHERPA/RoMEO [9], which provides a journal deposit policy, could be a good channel to use for the enhancement of policies on the posting of accepted articles on the third party. SHERPA/RoMEO is not yet commonly used in Asian countries; among Asian journals, more attention needs to be paid to how to use the SHERPA/RoMEO site effectively. Our result is similar to that of a study by Kim and Choi [10], who analyzed the digital standards of Asian journals registered in Directory of Open Access Journals, indicating that $85 \%$ of the journals $(1,689)$ had no digital deposit policy. Because the deposit policy differs depending on publishers and journals, most authors are confused over how to deposit their articles when the deposit is mandatory. Hence, Asian journal editors need to give more attention to improving this policy.

\section{Profit model information}

Revenue sources from the profit model information category should also be improved by the academic society journals. Traditionally, academic societies' publishing remains the most valued function, and revenue from publishing is usually used to support society members [11]. Business models or revenue sources (e.g., subscriptions, advertising) should be clearly stated on the journal homepage to avoid misleading authors on ethical feasibility. They should be separated from the journal content and the authors and should also not influence the editorial decision. According to a Trakya University analysis, three guidelines (marketing, intellectual property, data sharing) were not met by any 10 journals which were investigated [3]. In particular, because most Asian journals are published by non-profit organizations such as academic societies, journal editors' awareness of the profit model is low. This result also showed that these business model components should receive more attention compared to other parts because none of the three items are well practiced, regardless of country.

\section{Limitation}

The limitation of this study is that the journal homepage was the only part that was checked and examined to collect the data. Even though the study included an "information for authors" section or an author guideline on the homepage, the absence of that information on a journal homepage may not mean that a journal is not following good practice. Additionally, because of the limited resources, only the journals that clearly stated that they were published by a society were considered when collecting the raw data. Further study could be recommended that would also include surveys or interviews with journal editors regarding best practice compliance.

\section{Conclusion}

This study was focused only on academic society journals that are registered on the Science Citation Index Expanded. As such, it would not be representative of the overall global peerreviewed journal status. Because most small-society journals are operated by independent academic societies, society journals have difficulties in competing with the commercial publishers that invest a great deal in enhancing their infrastructure and publishing system. Society journal editors should continuously evaluate their journals regarding the "Principles of transparency and best practice in scholarly publishing" to keep up with a rapidly changing publishing environment. This research would be useful for editors of society journals when they upgrade or renovate their journal homepage to meet the best practice guidelines.

It would also help publication associations to understand how to help small societies meet the global standard. A positive step would be for society journal editors to receive regular training to keep pace with rapidly changing scholarly publication trends. Especially in Asia, the editor is less trained, and difficulties are involved in attaining proper information on this matter. Regional editors' associations, such as the Korean Council of Science Editors and Council of Asian Science Editors, could be the best channel to provide information on the latest best practice guidelines. Currently, Korean Council of Science Editors in Korea conducts regular editor training on how to apply the guideline effectively. If similar regional editors' associations can be created in other regions to actively share the latest information, more academic society journals can get the right information to meet the international publishing standards.

\section{Conflict of Interest}

No potential conflict of interest relevant to this article was reported. 


\section{Data Availability}

Dataset is available from the Harvard Dataverse at: https://doi. org/10.7910/DVN/TY2BME.

Dataset 1. Raw data of 33 items of "Principles of transparency and best practice in scholarly publishing" from 781 society journals indexed in the Science Citation Index Expanded.

\section{References}

1. International Association of Scientific, Technical, and Medical Publishers. STM statement on the increase of unethical and deceptive journal practice [Internet]. Den Haag: International Association of Scientific, Technical and Medical Publishers; 2018 [cited 2018 Dec 16]. Available from: https://www.stm-assoc.org/2018_08_09_STM_ statement_on_the_increase_of_unethical_and_deceptive_journal_practices.pdf

2. National Library of Medicine. FAQ: journal selection for MEDLINE indexing at NLM [Internet]. Bethesda: National Library of Medicine; 2018 [cited 2018 Dec 16]. Available from: https://www.nlm.nih.gov/lstrc/j_sel_faq. html

3. Huh S. The 14th European Association of Science Editors Conference, Bucharest 2018. Sci Ed 2018;5:155-8. https:// doi.org/10.6087/kcse.142

4. Open Access Scholarly Publishers Association. Principles of transparency and best practice in scholarly publishing [Internet]. The Hague: Open Access Scholarly Publishers
Association; 2018 [cited 2018 Dec 17]. Available from: https://oaspa.org/principles-of-transparency-and-bestpractice-in-scholarly-publishing-3/

5. Graf C, Wager E, Bowman A, Fiack S, Scott-Lichter D, Robinson A. Best practice guidelines on publication ethics: a publisher's perspective. Int J Clin Pract 2007;61:1-26. https://doi.org/10.1111/j.1742-1241.2006.01230.x

6. Kim SY, Yi HJ, Huh S. Current and planned adoption of data sharing policies by editors of Korean scholarly journals. Sci Ed 2019;6:19-24. https://doi.org/10.6087/kcse.151

7. PLOS. Editorial and publishing policies: data availability [Internet]. San Francisco: PLOS [cited 2018 Dec 18]. Available from: https://www.plos.org/editorial-publishing-policies

8. Vines TH, Andrew RL, Bock DG, et al. Mandated data archiving greatly improves access to research data. FASEB J 2013;27:1304-8. https://doi.org/10.1096/fj.12-218164

9. SHERPA/RoMEO. Publisher copyright policies \& self-archiving [Internet]. [Place unknown]: SHERPA/RoMEO [cited 2018 Dec 17]. Available from: http://www.sherpa. ac.uk/romeo

10. Kim S, Choi H. Status of digital standards, licensing types, and archiving policies in Asian open access journals registered in Directory of Open Access Journals. Sci Ed 2019; 6:41-6. https://doi.org/10.6087/kcse.154

11. Johnson R, Watkinson A, Mabe M. The STM report: an overview of scientific and scholarly journal publishing. The Hague: International Association of Scientific, Technical and Medical Publishers; 2018. 